\title{
ENGEVISTA
}

Página da revista: http://www.uff.br/engevista/seer/

\section{Influência da temperatura de secagem de uvaia (Eugenia pyriformis) em camada de espuma}

\section{Influence of drying temperature on uvaia (Eugenia pyriformis) foam layer}

\author{
Cesar Vinicius Toniciolli Rigueto ${ }^{1}$ \\ Loraine Micheletti Evaristo ${ }^{2}$ \\ Claudineia Aparecida Queli Geraldi ${ }^{3}$ \\ Lara Covre ${ }^{4}$
}

\begin{abstract}
Resumo: O Brasil é considerado um dos maiores produtores de frutas tropicais do mundo, entretanto, perdas relevantes pós-colheita ocorrem principalmente devido a técnicas inadequadas de conservação. Nesse sentido, a secagem destaca-se por ser um método simples e eficaz no controle da deterioração de alimentos. Assim, objetivou-se, com este trabalho, propor e ajustar modelos matemáticos às curvas de secagem em camada de espuma da polpa de uvaia em diferentes temperaturas, como também, analisar a influência da temperatura de secagem na concentração de vitamina $C$ nas polpas em pó. A secagem foi realizada em estufa de circulação de ar nas temperaturas de 50,60,70 e $80^{\circ} \mathrm{C}$. Os modelos matemáticos Lewis, Midilli e Kucuk e Page foram ajustados aos resultados experimentais, sendo que, o melhor ajuste foi obtido utilizando o modelo de Page. Os pós de fruta apresentaram $\mathrm{pH}$ ácido, o teor de vitamina $\mathrm{C}$ diminuiu conforme o aumento das temperaturas e o teor de cinzas foi influenciado pela adição de agentes espumantes.
\end{abstract}

Palavras-chave: Uvaia; Secagem; Modelagem matemática; Vitamina C.

\begin{abstract}
Brazil is considered one of the largest tropical fruit producers in the world, however, significant post-harvest losses are due to inadequate conservation techniques. In this sense, the drying stands out as being a simple and effective method in the control of food spoilage. Thus, the objective of this study was to propose and adjust mathematical models to the drying curves of the foam layer of the uvaia pulp at different temperatures, as well as to analyze the influence of drying temperature on vitamin $\mathrm{C}$ concentration in powdered pulps. The drying was carried out in an air circulation oven at temperatures of $50,60,70$ and $80^{\circ} \mathrm{C}$. The mathematical models Lewis, Midilli and Kucuk and Page were adjusted to the experimental results, the best fit was obtained using Page model. Fruit powders presented acid $\mathrm{pH}$, vitamin $\mathrm{C}$ content decreased as temperatures increased, and ash content was influenced by the addition of foaming agents.
\end{abstract}

Keywords: Uvaia; Drying; Mathematical modeling; Vitamin C.

\footnotetext{
${ }^{1}$ FAPEMAT - Fundação de Amparo à Pesquisa do Estado de Mato Grosso

${ }^{2}$ FAPEMAT - Fundação de Amparo à Pesquisa do Estado de Mato Grosso

${ }^{3}$ FAPEMAT - Fundação de Amparo à Pesquisa do Estado de Mato Grosso

${ }^{4}$ FAPEMAT - Fundação de Amparo à Pesquisa do Estado de Mato Grosso
}

ENGEVISTA, V. 20, n.4, p.537-547, Outubro 2018. 


\section{Introdução}

As frutas possuem grande importância nutricional para a alimentação humana, no qual são recomendadas pela disponibilidade de carboidratos, minerais, fibras, carotenoides, vitaminas C, substâncias fenólicas e de ação antioxidante, responsáveis pela prevenção de diversas doenças quando consumidas regularmente (Vieira, 2010).

O Brasil é um dos maiores produtores de frutas tropicais, porém, grande parte dessas frutas sofre deterioração em poucos dias, prejudicando sua comercialização, principalmente tratando-se de longas distâncias (Santos; Coelho; Carreiro, 2008). A deterioração ocorre principalmente devido ao alto teor de água presente nos frutos, por isso, faz-se necessário a aplicação de métodos de conservação com a finalidade de aumentar a durabilidade do alimento, evitando sua deterioração por processos microbianos e químicos (Santos et al., 2013).

Na conservação de alimentos o controle de umidade é de extrema importância, pois tem influência direta na atividade metabólica, multiplicação, resistência e sobrevivência de microrganismos presentes nos alimentos (Ramos et al., 2008). Ainda, dados da FAO (2015) as perdas de frutos pós-colheita no Brasil chegam em média a 30\%, além disso, esse elevado nível de desperdício contribui consideravelmente para o uso desnecessário de água (Agência Brasil, 2015).

A uvaia (Eugenia pyriformis) é uma espécie arbórea que produz frutos comestíveis de sabor agradável, e que possui características adequadas ao uso na arborização urbana. Seus frutos são denominados também de ubaia, uvalha, uvaia-do-mato e uvalheira (Rufino, 2008).

Tendo em vista a sazonalidade da uvaia, é importante que, utilizando-se métodos e procedimentos apropriados, consiga-se disponibilizar a polpa desta fruta para consumo durante todo o ano, permitido o abastecimento de regiões não produtoras. Além disso, o cultivo dessa fruta pode gerar um aumento da renda familiar dos produtores, pois, a maior parte dessa frutífera é cultivada por pequenas e médias propriedades, valorizando a agricultura familiar.

Nesse sentido, a secagem é um dos processos de conservação de alimentos mais antigos, sendo muito vantajoso, visando principalmente a redução dos teores de umidade e consequentemente dificultando o desenvolvimento de reações físico-químicas e crescimento microbiano (Zotarelli, 2014). Ainda, a secagem em camada de espuma, que é realizada empregando agentes espessantes favorecem curtos tempos de secagens a baixas temperaturas, devido a estrutura da espuma apresentar bolhas de ar, que tornam melhor a passagem da água, não alterando a estrutura do alimento durante o processo, aumentando consideravelmente sua área exposta ao ar quente, facilitando a saída da água e conservando melhor o sabor e valor nutricional (Roncheti, 2014).

Desta forma, o presente estudo objetivou analisar a influência da temperatura e cinética de secagem em camada de espuma, bem como as propriedades físico-químicas da polpa de uvaia 
após o processo de secagem, contribuindo com o desenvolvimento cientifico e tecnológico, uma vez que dados reportados sobre essa fruta são escassos na literatura.

\section{Material e métodos}

Para o desenvolvimento deste trabalho foram utilizadas como matérias-primas os frutos de uvaia, provenientes do mercado local de Colíder-MT. As amostras foram preparadas e analisadas no LMPPB (Laboratório de Matérias-Primas para produção de biodiesel) da Universidade do Estado de Mato Grosso (UNEMAT), campus de Barra do Bugres.

\subsection{Preparo da polpa e obtenção da espuma}

Os frutos foram selecionados de acordo com o estágio de maturação, sendo estes higienizados em água corrente, despolpados manualmente, e posteriormente armazenados sob congelamento a temperatura de $-18^{\circ} \mathrm{C}$ em freezer comercial até as próximas etapas de processamento para desenvolvimento das análises.

Posteriormente, foram triturados e homogeneizados em liquidificador comercial. Para a elaboração da espuma foram testadas as concentrações de 4,0, 4,5 e 5\% (m/m) de emulsificante, com auxílio de uma batedeira comercial, por 8 minutos em velocidade máxima. A concentração de 4,5\% de emulsificante foi selecionada, por apresentar melhor estabilidade. A espuma formada foi distribuída em placas de Petri e levadas para uma estufa de circulação de ar para secagem em temperatura controlada.

\subsection{Secagem e obtenção do pó}

Amostras de $10 \mathrm{~g}$ de espuma foram cuidadosamente espalhadas em placas de Petri e levadas em estufa de circulação forçada de ar (CienLab, CE-480) à temperatura de 50, 60, 70 e $80{ }^{\circ} \mathrm{C}$. As espumas das polpas secas foram retiradas das placas de Petri com auxílio de uma espátula, foram acondicionadas e identificadas quanto ao tipo de material, data e condições experimentais.

\subsection{Estudo da cinética de secagem}

As curvas de secagem foram estabelecidas para as amostras submetidas às condições descritas, mediante acompanhamento da perda de umidade registrada através da variação da massa das amostras em intervalos de tempo de 15 minutos. As perdas de massa durante a secagem foram obtidas com o auxílio de uma balança semi-analítica com precisão de 0,0001 g. Os ensaios foram prolongados até que atingissem condições de equilíbrio (massa constante). A razão de umidade (RU) foi determinada conforme a Equação 1.

$$
R U=\frac{\left(U-U_{e}\right)}{\left(U_{i}-U_{e}\right)} \quad \text { (Equação 1) }
$$

$\mathrm{U}=$ teor de água do produto, decimal b.s; Ui= teor de água inicial do produto, decimal b.s; $\mathrm{Ue}=$ teor de água de equilíbrio do produto, decimal b.s. 


\subsection{Modelagem matemática}

Para avaliar o comportamento da perda de umidade ao longo do tempo foram utilizados modelos semi-empíricos. Considerando a umidade de equilíbrio como a umidade atingida quando a taxa de secagem se anula, foram calculadas as razões de umidade (RU). Logo, utilizou-se o programa Excel para a realização dos cálculos e modelagem. Para representar a cinética de secagem das polpas da uvaia em camada de espuma, foram utilizados os modelos matemáticos de Lewis (1921), Midilli e Kucuk (2002) e Page (1949), conforme apresentados na Tabela 1.

Tabela 1: Modelos matemáticos utilizados para descrever a cinética de secagem

\begin{tabular}{|c|c|c|}
\hline Designação do modelo & Modelo & Equação \\
\hline Modelo de Lewis & $X_{a d}=\exp (-k t)$ & $(2)$ \\
\hline Modelo de Midilli e Kucuk & $X_{a d}=a \exp \left(-k t^{n}\right)+b t$ & $(3)$ \\
\hline Modelo de Page & $X_{a d}=\exp \left(-k t^{n}\right)$ & (4) \\
\hline
\end{tabular}

$X_{a d}=$ teor de umidade (adimensional); $\mathrm{t}=$ tempo de secagem $(\mathrm{min}) ; \mathrm{k}=$ coeficiente de secagem $\left(\min ^{-1}\right) ; \mathrm{a}, \mathrm{b}, \mathrm{n}=$ constante do modelo (adimensional).

\subsection{Análises físico-químicas}

As polpas secas de uvaia foram submetidas às análises de: pH (método 014/IV), teor de umidade por gravimetria (método 014/IV), teor de vitamina C (método 364/IV), teor de cinzas (método 364/IV) e teor de acidez (método 310/IV), conforme o manual do Instituto Adolf Lutz (2008). Todas as análises foram realizadas em triplicata.

\section{Resultados e Discussão}

\subsection{Cinética de secagem}

As curvas de secagem das polpas de uvaia estão apresentadas na Figura 1, na forma adimensional do conteúdo de umidade (RU versus tempo). Ainda pode-se observar que o período de secagem foi dependente do tempo e temperatura.

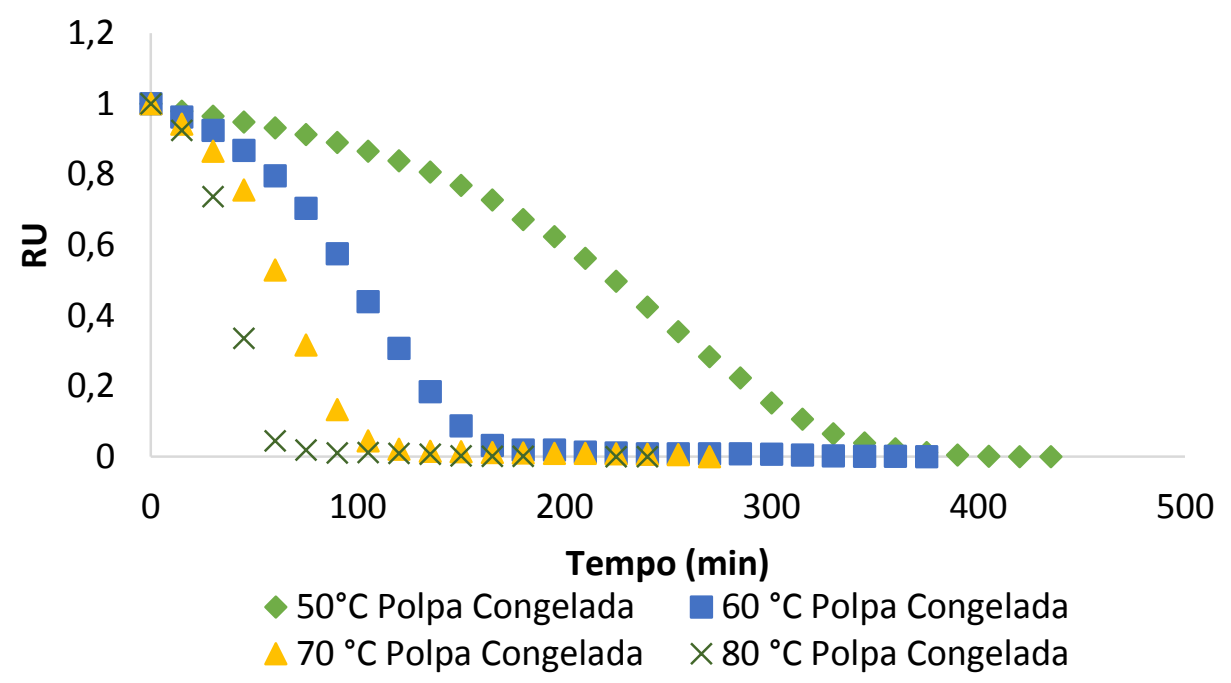

Figura 1: Curvas de secagem em camada de espuma da polpa de uvaia nas temperaturas de 50 , 60,70 e $80{ }^{\circ} \mathrm{C}$ 
As espumas de uvaia secas a $50{ }^{\circ} \mathrm{C}$, o tempo necessário para reduzir o teor de água foi de $435 \mathrm{~min}$, já para a temperatura de $80^{\circ} \mathrm{C}$ o tempo foi de $150 \mathrm{~min}$. O aumento da temperatura favoreceu uma redução do tempo de secagem, resultando em curvas mais inclinadas devido a maior quantidade de calor transferido do ar para o material.

Segundo Thuwapanichayanan, Prachayawarakorn e Soponronnarit (2008), o transporte da água do interior da espuma ocorre por capilaridade e difusão de vapor. Ainda, Brooker et al. (1992) afirmam que nesta fase da secagem, os fatores dependem apenas das condições externas do processo como: temperatura, velocidade e umidade relativa do ar.

A remoção de água do interior da espuma de uvaia para a superfície exposta não é suficiente para manter a superfície úmida, motivo pelo qual se inicia o período de taxa de secagem decrescente conduzido pelo mecanismo de difusão, onde nele, segundo Brooker et al. (1992) a transferência de calor não é compensada pela transferência de massa porque a resistência interna ao transporte de umidade se torna maior do que a resistência externa e a temperatura do produto aumenta podendo atingir a temperatura do ar de secagem.

\subsection{Modelagem matemática}

Na Tabela 2 estão apresentados os parâmetros dos modelos matemáticos de Lewis, Midilli e Kucuk e Page, ajustados aos dados experimentais da secagem das espumas de uvaia, além dos coeficientes de correlação e erros médios.

Tabela 2: Parâmetros dos modelos matemáticos ajustados para a cinética de secagem das polpas secas de uvaia

\begin{tabular}{|c|c|c|c|c|c|}
\hline \multicolumn{6}{|c|}{ Temperaturas } \\
\hline Modelos & Parâmetros & $50^{\circ} \mathrm{C}$ & $60^{\circ} \mathrm{C}$ & $70^{\circ} \mathrm{C}$ & $80^{\circ} \mathrm{C}$ \\
\hline \multirow{3}{*}{$\begin{array}{l}\text { Modelo de } \\
\text { Lewis }\end{array}$} & $\mathrm{k}\left(\min ^{-1}\right)$ & 0,004062 & 0,012537 & 0,019883 & 0,032137 \\
\hline & $\mathrm{R}^{2}$ & 0,947849 & 0,957388 & 0,949049 & 0,940056 \\
\hline & Erro & 9,322384 & 6,951048 & 5,341630 & 3,998744 \\
\hline \multirow{6}{*}{$\begin{array}{c}\text { Modelo de } \\
\text { Midilli e } \\
\text { Kucuk }\end{array}$} & $\mathrm{a}$ & 0,983070 & 1,046410 & 1,081186 & 1,000336 \\
\hline & $\mathrm{b}$ & 0,000000 & 0,000000 & 0,000004 & 0,000012 \\
\hline & $\mathrm{k}\left(\min ^{-1}\right)$ & 0,000021 & 0,000427 & 0,002902 & 0,000750 \\
\hline & $\mathrm{n}$ & 1,943860 & 1,662935 & 1,403148 & 1,913568 \\
\hline & $\mathrm{R}^{2}$ & 0,990240 & 0,993581 & 0,989136 & 0,990652 \\
\hline & Erro & 1,789128 & 0,911153 & 0,823924 & 0,354382 \\
\hline \multirow{4}{*}{$\begin{array}{l}\text { Modelo de } \\
\text { Page }\end{array}$} & $\mathrm{k}\left(\min ^{-1}\right)$ & 0,000019 & 0,000180 & 0,000141 & 0,001096 \\
\hline & $\mathrm{n}$ & 1,964405 & 1.835803 & 2,085366 & 1,813573 \\
\hline & $\mathrm{R}^{2}$ & 0,990020 & 0,994213 & 0,996881 & 0,990998 \\
\hline & Erro & 1,675541 & 0,746267 & 0,368908 & 0,402754 \\
\hline
\end{tabular}

Conforme pode ser observado na Tabela 2, os modelos de Page e o de Midilli e Kucuk apresentaram os melhores ajustes, em relação aos modelos empregados. Ainda, o modelo de Page apesentou a melhor correlação e o menor erro médio estimado em todas as condições estudadas. 
O modelo de Lewis não representou satisfatoriamente a cinética de secagem em camada de espuma da polpa de uvaia, apresentando uma baixa correlação e maior erro em todas as condições estudadas em relação aos demais modelos (Tabela 2).

A espuma da polpa congelada de uvaia para o modelo de Page submetida à secagem a $70^{\circ} \mathrm{C}$ apresentou maior correlação e o menor erro médio foi descrito pelo modelo de Midilli e Kucuk submetida à secagem a $80^{\circ} \mathrm{C}$. Segundo Samapundo et al. (2007) valores inferiores a $10 \%$ de erro médio relativo indicam boa adequabilidade para fins práticos, logo, constata-se que o modelo proposto é apropriado para descrever o fenômeno de secagem em camada de espuma da polpa de uvaia e ainda determinar o ponto de transição entre o período de secagem constante e decrescente.

Para a temperatura de $80^{\circ} \mathrm{C}$ observou-se uma redução de água crítica, em que segundo Baptestini et al., (2015) ocorre provavelmente, devido à falta de estabilidade da espuma durante o aquecimento, uma vez que sua instabilidade resulta no colapso celular danificando seriamente a operação de secagem. Foi possível notar a formação de uma crosta dura sobre as amostras, perdendo a estrutura porosa esperada, além disso, o pó formado nas placas era de difícil remoção.

Nas Figuras 2, 3, 4 e 5 estão apresentadas as curvas ajustadas segundo o modelo de Lewis, Midilli e Kucuk e Page, nas condições de 50, 60, 70 e $80^{\circ} \mathrm{C}$, respectivamente, aos dados experimentais da cinética de secagem da espuma da polpa de uvaia.

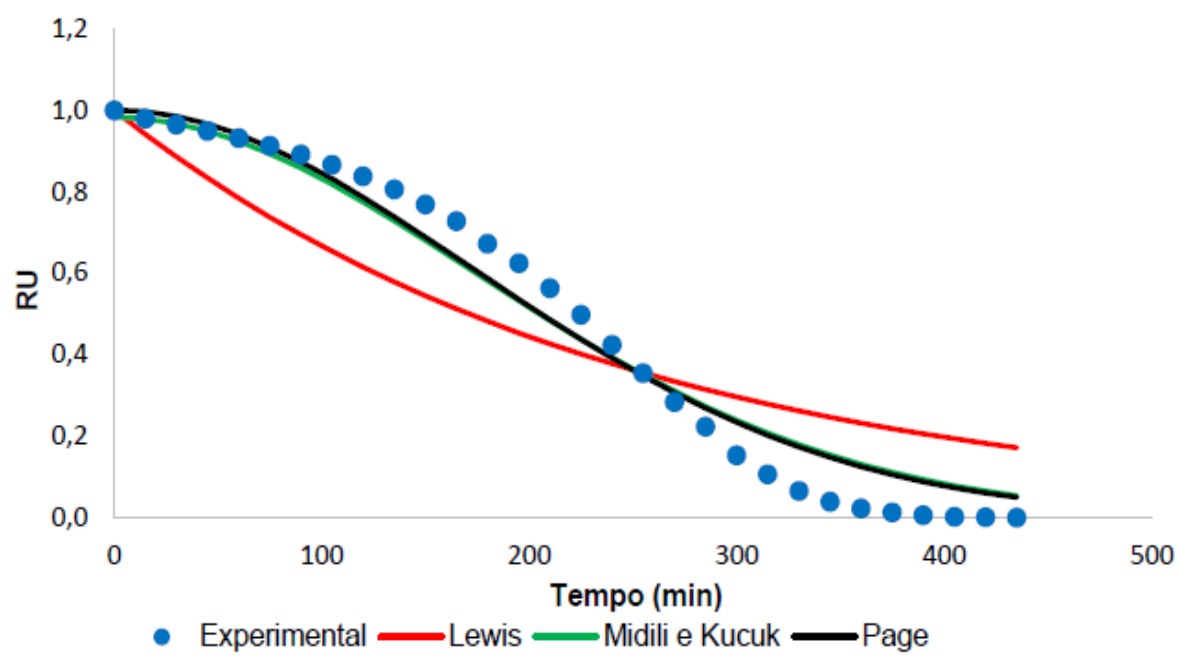

Figura 2: Ajustes dos modelos de Lewis, Midilli e Kucuk e Page para secagem em camada de espuma da polpa de uvaia a $50^{\circ} \mathrm{C}$ 
ISSN: $1415-7314$

ISSN online: $2317-6717$

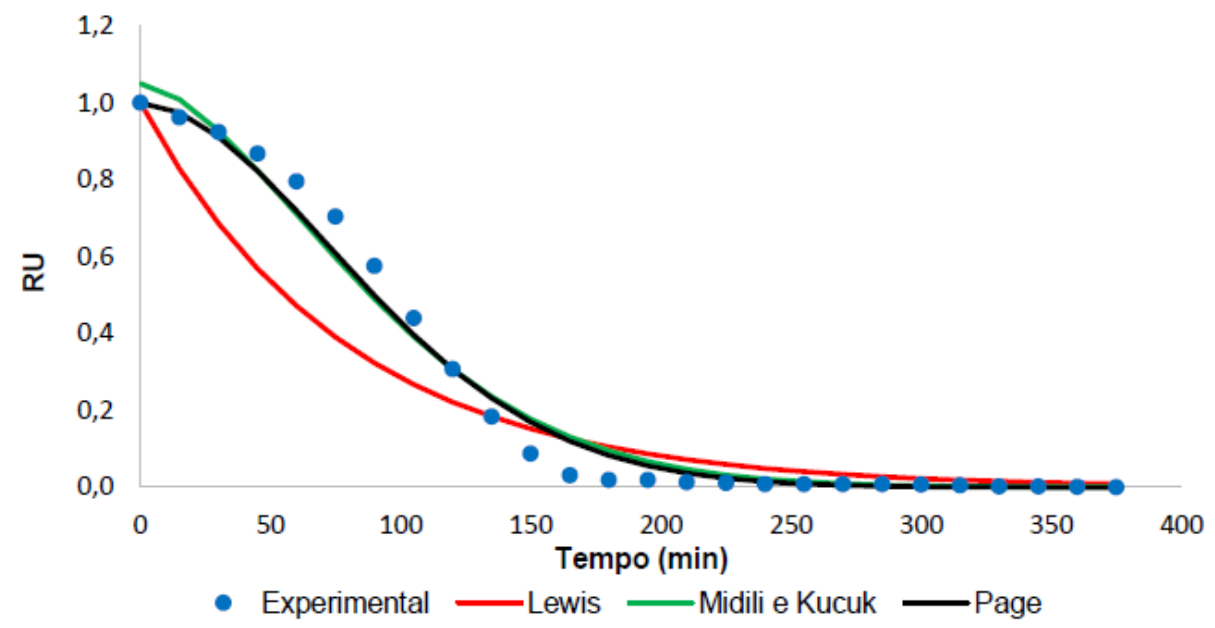

Figura 3: Ajustes dos modelos de Lewis, Midilli e Kucuk e Page para secagem em camada de espuma da polpa de uvaia a $60{ }^{\circ} \mathrm{C}$

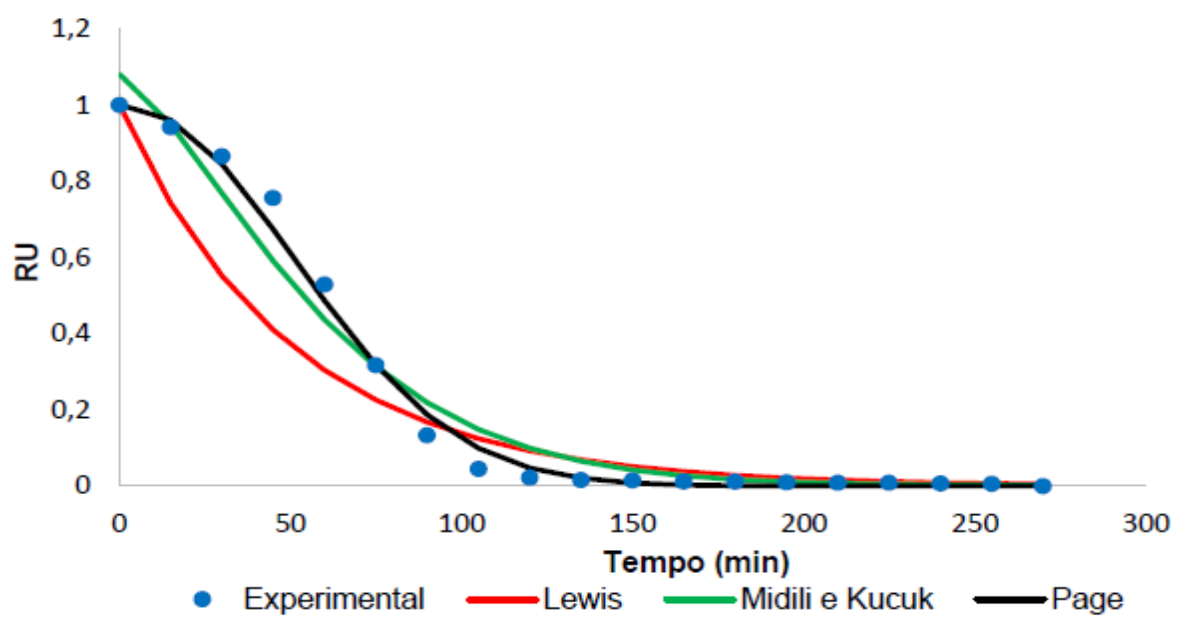

Figura 4: Ajustes dos modelos de Lewis, Midilli e Kucuk e Page para secagem em camada de espuma da polpa de uvaia a $70{ }^{\circ} \mathrm{C}$

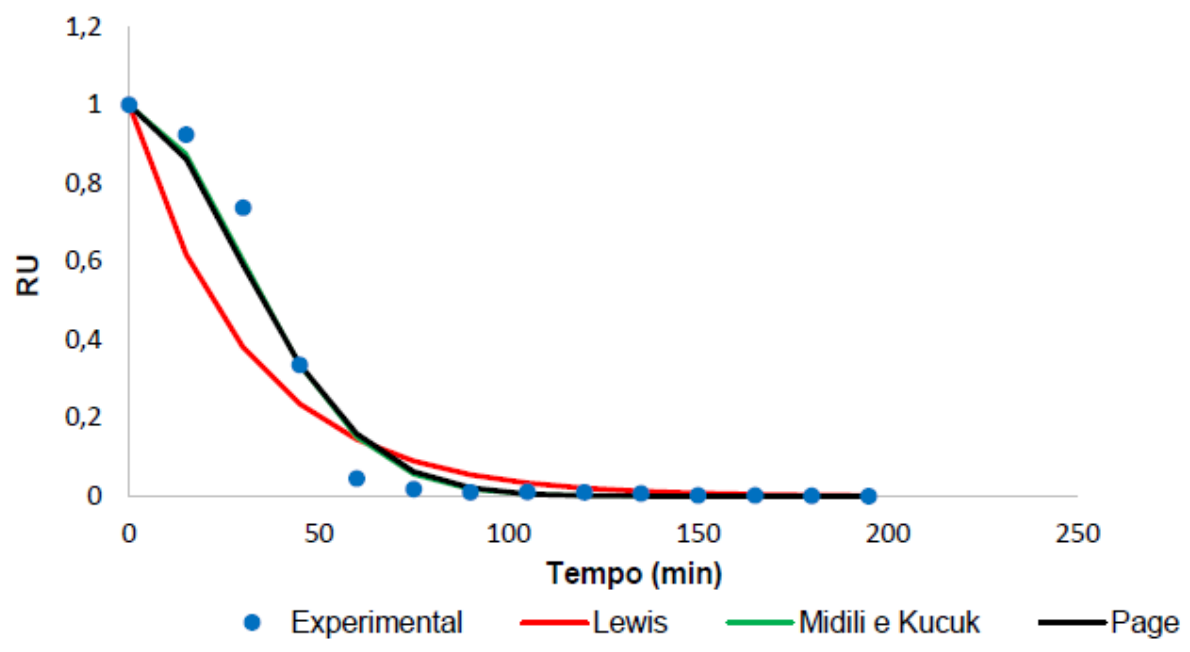


Figura 5: Ajustes dos modelos de Lewis, Midilli e Kucuk e Page para secagem em camada de espuma da polpa de uvaia a $80^{\circ} \mathrm{C}$

Os perfis das curvas de secagem confirmam o melhor ajuste dos dados experimentais ao modelo de Page.

Analisando um fruto semelhante, Silva et al (2015) verificaram nos ajustes de sete modelos empíricos na secagem de polpa de achachairu, que o modelo de Page também foi o que forneceu valores de correlação mais elevados, bem como menor erro médio.

\subsection{Análises físico-químicas da polpa seca}

Os parâmetros avaliados da caracterização físico-química da polpa in natura e do pó produzido a partir da espuma composta de polpa de uvaia congelada com 4,5\% de emustab, desidratada nas temperaturas de 50,60, 70 e $80^{\circ} \mathrm{C}$, estão apresentados na Tabela 3.

Tabela 3: Caracterização físico-química da polpa de uvaia in natura e após secagem em camada de espuma

\begin{tabular}{c|c|c|c|c|c}
\hline \multirow{2}{*}{ Análise } & $\begin{array}{c}\text { Polpa in } \\
\text { natura }\end{array}$ & \multicolumn{4}{c}{ Polpas secas } \\
\hline SST $\left({ }^{\circ}\right.$ Brix) & $7,75 \pm 0,33$ & $50{ }^{\circ} \mathrm{C}$ & $60{ }^{\circ} \mathrm{C}$ & $70{ }^{\circ} \mathrm{C}$ & $80{ }^{\circ} \mathrm{C}$ \\
\hline Umidade (\%) & $87,53 \pm 0,02$ & $83,2 \pm 0,90$ & $83 \pm 0,09$ & $85 \pm 0,96$ & $86,48 \pm 0,38$ \\
\hline ATT (\%) & $0,7 \pm 0,08$ & $4,0 \pm 0,08$ & $4,5 \pm 0,08$ & $4,6 \pm 0,12$ & $4,6 \pm 0,16$ \\
\hline pH & $3,15 \pm 0,01$ & $3,21 \pm 0,02$ & $3,19 \pm 0,01$ & $3,32 \pm 0,01$ & $3,32 \pm 0,02$ \\
\hline Cinzas (\%) & $0,24 \pm 0,02$ & $2,62 \pm 0,19$ & $2,95 \pm 0,14$ & $3,24 \pm 0,13$ & $3,05 \pm 0,03$ \\
\hline Vitamina C (mg) & $59,79 \pm 0,44$ & $289,43 \pm 2,75$ & $255,52 \pm 1,53$ & $165,29 \pm 1,72$ & $59,8 \pm 1,61$ \\
\hline \multicolumn{7}{c}{ SST: Sólidos solúveis totais; ATT: Acidez total titulável. }
\end{tabular}

Os resultados obtidos na caracterização da polpa de uvaia in natura estão de acordo com os resultados de Sartori et al. (2010), que obtiveram sólidos solúveis totais 7,5 ${ }^{\circ}$ Brix. Valor superior foi encontrado por Branco et al. (2016), apresentando $10,97^{\circ} \mathrm{Brix}$, tal diferença pode ser evidenciada pelo estágio de maturação em que a fruta se encontra, região de cultivo, clima, solo, dentre outros fatores.

Em estudos realizados por Coutinho e Pascolatti (2014), com a uvaia in natura e congelada, foram obtidos teores de umidade de 84,52 e $87,65 \%$, respectivamente. Esse aumento na umidade pode ser compreendido pela maior retenção de água da fruta congelada comparada a in natura.

A determinação da acidez total titulável indica o grau de conservação dos alimentos, sendo que o valor obtido de $0,7 \%$ de acidez da polpa in natura se mostrou próximo aos $0,46 \%$ encontrado por Coutinho e Pascolatti (2014). Ainda, nota-se que o processo de secagem aumentou a acidez das amostras de polpa em pó, resultando em uma acidez maior que a amostra fresca, devido à eliminação de quase toda a parte aquosa da polpa. Tal fato também foi verificado por Leal (2015), na secagem de polpas de abacaxi, acerola e carambola, utilizando camada de espuma nas temperaturas de 50,60 e $70^{\circ} \mathrm{C}$. 
Como esperado, a polpa de uvaia apresentou valor de $\mathrm{pH}$ variando de 3,15 a 3,32 caracterizando meio ácido, e quando comparando em função das quatro temperaturas analisadas manteve-se o valor semelhante ao resultado obtido na amostra congelada.

As polpas de uvaia secas a 50,60,70 e $80^{\circ} \mathrm{C}$ apresentaram teores de cinzas iguais a 2,62, 2,95, 3,24 e 3,05, respectivamente. Pode-se observar que os valores encontrados são superiores ao valor obtido da polpa in natura que foi de $0,24 \%$, sendo que tal aumento deve-se a adição de emulsificante às amostras de polpa, que contribuem para o aumento de gordura, conforme Maruyama et al. (2006). Em estudos realizados por Coutinho e Pascolatti (2014), o teor de cinzas para polpa de uvaia in natura foi de $0,26 \%$.

Os resultados para vitamina $\mathrm{C}$ foram de $56,79 \mathrm{mg} / 100 \mathrm{~g}$ para amostras polpa in natura, conforme a Tabela 4. O teor de vitamina C obtido por Coutinho e Pascolatti (2014) foi de 93,83 mg/100 g. Segundo Chambers et al. (1996), a fruta submetida a baixas temperaturas pode desenvolver uma maior estabilidade do ácido ascórbico, aumentando seu teor de vitamina, analogamente, pode ocorrer uma diminuição de vitaminas quando submetido a temperaturas de aquecimento e luminosidade. De posse dessa informação, nota-se que a elevação da temperatura provocou uma diminuição no teor de vitamina C. Declínios similares foram relatados por outros autores em tomate (Fernandes et al., 2014), repolho (Kadam; Lata; Pandey, 2005) e batata (Mehta et al., 2007). Portanto, a condição de secagem mais adequada para retenção da concentração da vitamina $\mathrm{C}$ nas polpas em estudo e nas condições estudadas foi na temperatura de $50^{\circ} \mathrm{C}$.

\section{Conclusão}

De acordo com os dados obtidos, conclui-se que o aumento da temperatura do de secagem favoreceu a redução no tempo de secagem das espumas de uvaia. Com relação à modelagem matemática, os modelos de Page e o de Midilli e Kucuk se ajustaram bem aos dados experimentais de secagem nas quatro temperaturas estudadas.

Nas análises físico-químicas, o fruto da uvaia in natura demonstrou caráter ácido, com elevação dos teores de acidez e cinzas após a secagem em camada de espuma. Além disso, as polpas de uvaia secas a $50^{\circ} \mathrm{C}$ apresentaram maior retenção de vitamina $\mathrm{C}$ devido a menor temperatura de exposição das espumas.

\section{Referências}

AGÊNCIA BRASIL. 2015. FAO quer reduzir a perda e o desperdício de alimentos no Brasil. Disponível em: http://agenciabrasil.ebc.com.br/economia/noticia/2015-04/domingo-editada-faoquer-reduzir-perdas-de-alimentos-no-brasil Acessado em: 19 de fev. de 2018.

BAPTESTINI, F. M., CORRÊA, P. C., JUNQUEIRA, M. S., RAMOS, A. F., VANEGAS, J. D. B. \& COSTA, C. F. 2015. Modelagem matemática da secagem de espuma de graviola. Revista Brasileira Engenharia Agrícola Ambiental, 19, 1203-1208.

BRANCO, I. G., KIKUCHI, T. T., ARGANDOÑA, E. J. S., MORAES, I. C. F. \& HAMINIUK, C. W. I. 2016. Drying kinetics and quality of uvaia (Hexachlamys edulis (O. Berg)) powder 
obtained by foam-mat drying. International Journal of Food Science and Technology 51, 17031710 .

BROOKER, D. B., BAKKER-ARKEMA, F. W. \& HALL, C. W. 1992. Drying and storage of grains and oilseeds. Westport: The AVI Publishing Company.

CHAMBERS, S. J., NIGEL, L., PLUMB, G. W. \& WILLIAMSON, G. 1996. Evaluation of the antioxidant properties of a methanolic extract from juice plus fruit and juice plus vegetable (dietary supplements). Food Chemistry, 57, 271-274.

COUTINHO, A. M. \& PASCOLATTI, Y. S. 2014. Caracterização físico-química e análise antioxidante da polpa de uvaia (Eugenia pyriformis Cambess). Dissertação de Graduação. Universidade Tecnológica Federal do Paraná.

FERNANDES, R. V. B., QUEIROZ, F., BOTREL, D. A., ROCHA, V. V., SOUZA, V. R. \& LIMA, C. F. 2014. Estudo da adição de albumina e da temperatura de secagem nas características de polpa de tomate em pó. Semina: Ciências Agrárias, 35, 1267-1278.

INSTITUTO ADOLFO LUTZ. 2008. Métodos físico-químicos para análise de alimentos, São Paulo, Instituto Adolfo Lutz.

KADAM, D. M., LATA, D. V. K. S. \& PANDEY, A. K. 2005. Influence of different treatments on dehydrated cauliflower quality. International Journal of Food Science and Technology, 40, 849-856.

LEAL, A. K. 2015. Cinética de secagem das polpas de abacaxi, acerola e carambola através do método de camada de espuma. Dissertação de Graduação. Universidade do Estado de Mato Grosso.

LEWIS, W. K. 1921. The rate of drying of solids materials. The Journal of Industrial and Engineering Chemistry, 13, 427-432.

MARUYAMA, L.Y., CARDARELLI, H. R., BURITI, F. C. A. \& SAAD, S. M. I. 2006. Textura instrumental de queijo petit-suisse potencialmente probiótico: influência de diferentes combinações de gomas. Ciência e Tecnologia de Alimentos, 26, 386-393.

MEHTA, M. B., MEHTA, B., BAPODRA, A. H. \& JOSHI, H. D. 2007. Effect of germination and heat processing on protein, riboflavin, vit-C and niacin content in peas, cowpea, red gram and wheat. Asian Journal of Home Science, 2, 34-38.

MIDILLI, A., KUCUK, H. \& VAPAR, Z. 2002. A new model for single-layer drying. Drying Technology, 20, 1503-1513.

PAGE, G. E. Factors influencing the maximum rates of air drying shelled corn in thin layers. 1949. Dissertação de Mestrado, Purdue University.

RAMOS, A. M., QUINTERO, A. C. F., FARAONI, A. S., SOARES, N. F. F. \& PEREIRA, J. A. M. 2008. Efeito do tipo de embalagem e do tempo de armazenamento nas qualidades físicoquímica e microbiológica de abacaxi desidratado. Alimentos e Nutrição, 19, 259-269.

RONCHETI, E. F. S. 2014. Estudo do processo de secagem em leito de espuma de cenoura, tomate, beterraba e morango. Dissertação de Mestrado, Universidade Federal do Espírito Santo.

RUFINO, M. S. M. 2008. Propriedades funcionais de frutas tropicais brasileiras não tradicionais. Dissertação de Doutorado, Universidade Federal Rural do Semi-Árido.

SAMAPUNDO, S., DEVLIEGHERE, F., MEULENAER, B., ATUKWASE, A., LAMBONI, Y. \& DEBEVERE, J. M. 2007. Sorption isotherms and isosteric heats of sorption of whole yellow dent corn. Journal of Food Engineering, 79, 168- 175.

SANTOS, C. A. A., COELHO; A. F. S. \& CARREIRO, S. C. 2008. Avaliação microbiológica de polpas de frutas congeladas. Ciência e Tecnologia de Alimentos, 4, 913-915. 
SANTOS, M. L., MACHADO, A. V., ALVES, F. M. S. \& COSTA, A. P. L. M. 2013. Estudo físico-químico de maçã desidratada em secador convectivo. Revista Verde de Agroecologia e Desenvolvimento Sustentável, 8, 30-37.

SARTORI, S., DONADIO, L. C., MARTINS, A. B. G. \& MORO, F. V. 2010. Uvaia: Série de Frutas Nativas, Jaboticabal, Funep.

SILVA, L. M. M., SOUSA, F. C., CASTRO, D. S., GOMES, J. P. \& ALMEIDA, F. A. C. 2015. Estudo experimental da secagem de polpa de achachairu em camada fina. Revista Gaia Scientia, 9, 151-155.

THUWAPANICHAYANAN, R., PRACHAYAWARAKORN, S. \& SOPONRONNARIT, S. 2008. Drying characteristics and quality of banana foam mat. Journal of Food Engineering, 86, 573-575.

VIEIRA, L. M., SOUSA, M. S. B., MANCINIFILHO, J. \& LIMA, A. 2010. Fenólicos totais e capacidade antioxidante. Revista Brasileira de Fruticultura, 33, 888-897.

ZOTARELLI; M. F. 2014. Produção e caracterização de manga desidratada em pó por diferentes processos de secagem. Dissertação de Doutorado. Universidade Federal de Santa Catarina. 